\title{
Preisträger des Ärzteverbandes Deutscher Allergologen 2011
}

\section{Erich-Fuchs-Preis}

Den im letzten Jahr erstmals vergebenen Erich-Fuchs-Preis für besondere Verdienste um Fortbildung und wissenschaftliche Erkenntnis in der Allergologie erhält 2011 posthum Prof. Dr. Karl-Heinz Schulz, der dem ÄDA von 1978 bis 1983 als zweiter Präsident vorstand. In den Jahren 1980 und 1982 war er zudem Präsident der ÄDAKongresse.

Schulz baute in den $50 e r$ Jahren die Abteilung für Allergologie an der Universitätshautklinik Hamburg auf und leitete diese bis zu seiner Pensionierung. Neben der Forschung machte er sich vor allem um die Aus- und Fortbildung verdient. Weit über Fachkreise hinaus erlangte Schulz Bekanntheit, als es ihm gelang, die Ursachen der Chlorakne aufzuklären, eine toxische Reaktion auf Dioxin, die nach dem Unglück von Seveso in aller Munde war. Karl-Heinz Schulz ist am 9. Juli 2010 nach schwerer Krankheit im Alter von 88 Jahren verstorben. Sein Leben und seine Leistungen ließ Kollege Prof. Dr. Dr. Johannes Ring ab Seite 18 in Ausgabe 1/2011 des Allergo Journal Revue passieren.

\section{Viktor-Ruppert-Medaille}

Die Viktor-Ruppert-Medaille für bedeutende Beiträge zur gesundheitspolitischen Stellung der Allergologie erhielten gemeinsam die ehemaligen Vorsitzenden der ÄDARegionalgruppe Bonn, Prof. Dr. Joachim Sennekamp und PD Dr. Claus-E. Lange.

Sennekamp gründete 1980 in Bonn das allergologisch-immunologische Labor für Serumuntersuchungen auf exogen allergische Alveolitis und bronchopulmonale Mykosen mit einer ambulanten Allergiesprechstunde. Für seine wissenschaftliche Tätigkeit mit über 70 Publikationen wurde er im Jahr 2004 mit dem Dr.-Karl-HeyerPreis ausgezeichnet.

Lange promovierte und habilitierte an der Universität Bonn. Dort war er an der Aufklärung der durch Vinylchlorid bedingten Erkrankung beteiligt. Eine klinische Laufbahn schlug er aus und gründete stattdessen eine dermatologische Praxis in Bonn, die er bis zu seiner Pensionierung leitete.

Sennekamp und Lange gründeten die Bonner Regionalgruppe des ÄDA und leiteten sie 26 Jahre lang. In dieser Zeit organisierten sie mehr als 100 Fortbildungsveranstaltungen und richteten im Jahr 2000 den ÄDA-Kongress aus.
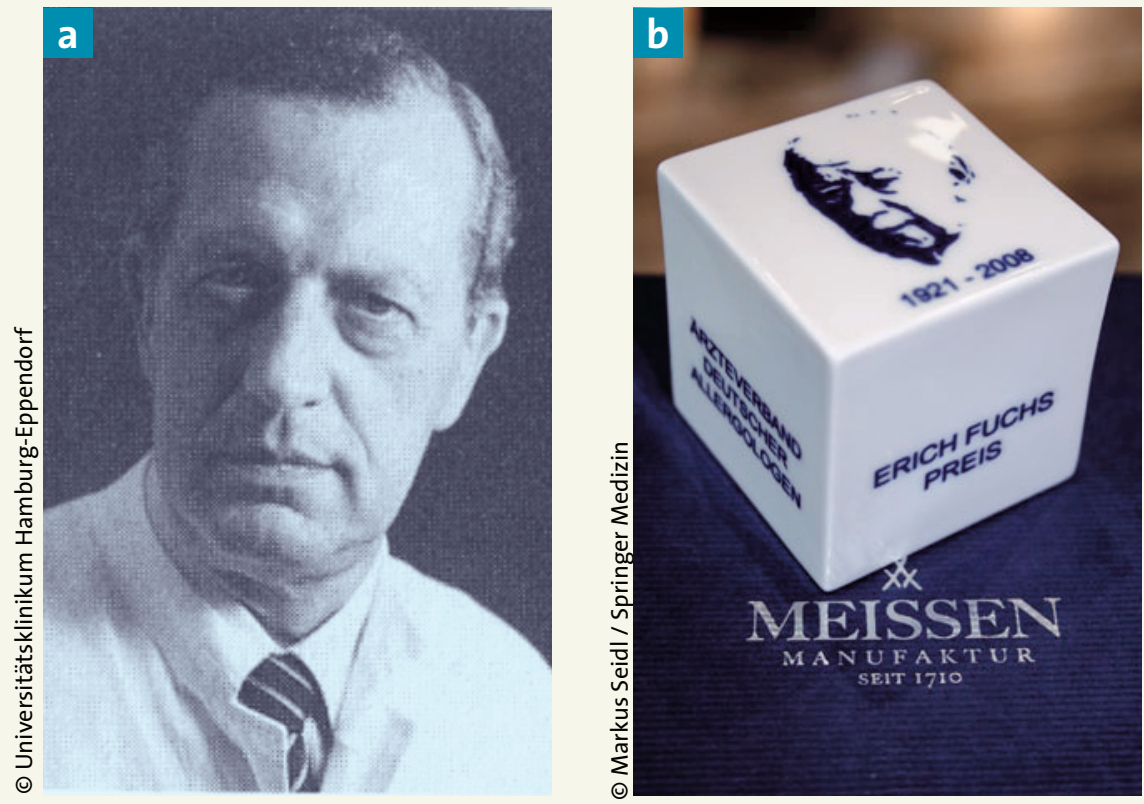

Prof. Dr. Karl-Heinz Schulz (*16. März 1922, †9. Juli 2010) (a) erhielt posthum den ErichFuchs-Preis 2011 (b). Der Preis wurde im letzten Jahr erstmals verliehen. Er soll Persönlichkeiten ehren, die sich in besonderer Weise um die Förderung von Forschung, Lehre und Fortbildung im Fach Allergologie verdient gemacht haben.

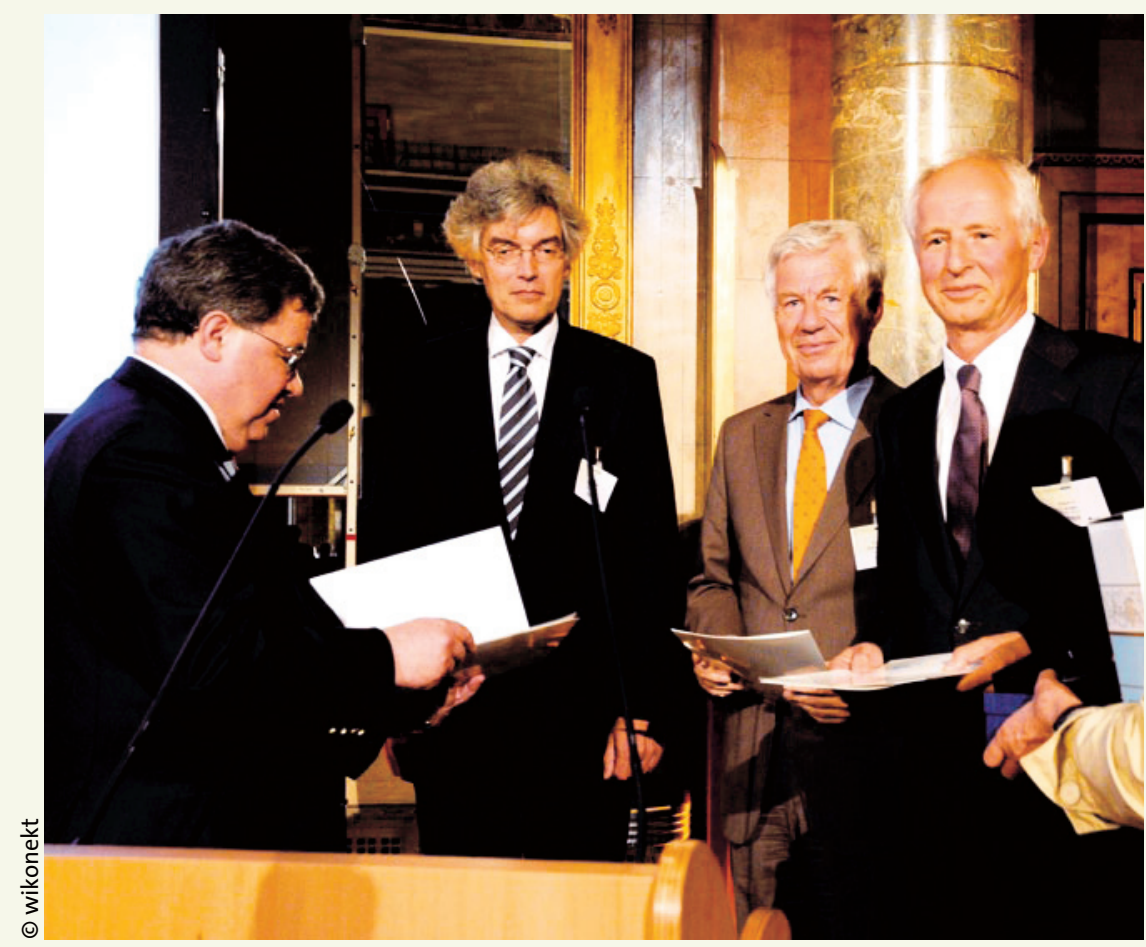

In der Mitte Prof. Dr. Joachim Sennekamp und PD Dr. Claus-E. Lange, die von ÄDA-Präsident Prof. Dr. Hans F. Merk, links, die Urkunden zur Viktor-Ruppert-Medaille erhalten. Sennekamp und Lange organisierten mehr als 100 Fortbildungsveranstaltungen. 